\title{
C242T Polymorphism in CYBA gene (p22phox) and risk of coronary artery disease in a population of Caucasian Italians
}

\author{
Sabina Nasti, Paolo Spallarossa, Paola Altieri, Silvano Garibaldi, Patrizia Fabbi, Luisa Polito, \\ Luca Bacino, Michele Brunelli, Claudio Brunelli, Antonio Barsotti and Giorgio Ghigliotti* \\ Department of Internal Medicine, Cardiology and Laboratory of Cardiovascular Biology, Genova University \\ School of Medicine, Genova, Italy
}

\begin{abstract}
Background: specific polymorphisms of genes regulating intracellular redox balance and oxidative stress are related to atherogenesis. Some studies have identified a relationship between progression of atherosclerosis and C242T mutation in CYBA gene coding for $\mathrm{p} 22^{\text {phox }}$, a subunit of the NADH $/ \mathrm{NADPH}$ oxidase system.

Design: we investigated whether the $\mathrm{C} 242 \mathrm{~T}$ nucleotide transition is associated with the presence of coronary artery disease (CAD) in a population of 494 Caucasian Italians undergoing coronary angiography to diagnose the cause of chest pain.

Results: the frequency of the T mutant allele that we found in 276 patients with angiographically documented CAD was significantly higher compared to what we observed in 218 subjects with normal coronary arteries (Controls) (respectively: 0.400 and $0.332, p<0.01)$. The prevalence of the $\mathrm{T}$ allele was even stronger when we compared: 1 ) early onset (age $\leqslant 55)$ vs late onset (age $\geqslant 65$ ) single-vessel CAD patients (respectively: 0.75 and $0.48, p<0.05$ ), and 2 ) the subgroup of CAD patients with at least one $\geqslant 98 \%$ stenosis in a coronary vessel vs those with no $\geqslant 98 \%$ stenosis in a coronary vessel (respectively: 0.425 and $0.365, p<0.05)$.

Conclusions: these results support the increased risk of developing early CAD and of having rapid progression of coronary stenosis in subjects carrying the C242T nucleotide transition among the Italian population.
\end{abstract}

Keywords: Oxidative stress, cardiovascular, gene, variant, NAD(P)H oxidase

\section{Introduction}

A wide variety of pro-atherogenic functions have been attributed to elevated plasma and intracellular levels of reactive oxygen species (ROS), and include: altering the endothelial cell (EC) function, promoting macrophage infiltration, and promoting smooth muscle cell (SMC) dysfunction. The pro-oxidant theory regarding the development of atherosclerosis proposed and demonstrated that oxidative stress, which is often

\footnotetext{
*Corresponding author: Giorgio Ghigliotti, M.D., Research Associate of Cardiology, Department of Internal Medicine, Cardiology - Genova University School of Medicine, Viale Benedetto XV, 6. 16132-Genova Italy. Tel: +39 010 3537934; Fax: +39 010 3538638; E-mail: gghiglio@cardio.dimi.unige.it.
}

associated with elevated plasma lipid levels, induces EC dysfunction, accumulation of inflammatory cells, and a decrease in atheroprotective nitric oxide (NO) levels $[2,17]$. Superoxide anion $\left(\mathrm{O}^{2-}\right)$ is a $\mathrm{ROS}$ which reacts with NO, the most potent endogenous vasodilator which also has a well-known endothelium protective property, thus producing peroxynitrite, a strong oxidant $[3,16]$. Furthermore, $\mathrm{O}^{2-}$ is involved in the oxidation of LDL, which promotes a robust inflammatory burst at the level of atherosclerotic plaques [8]. It has been proved that oxidants regulate and promote the expression of genes that are directly involved in the pathogenesis of atherosclerosis by binding to specific transcription factors, such as the nuclear factor (NF) kappa B. $22^{\text {phox }}$ is a subunit of the NADH/NAD(P)H oxidase system, a sophisticated enzymatic complex which 
represents the main source of $\mathrm{O}^{2-}$ in human blood vessels. The NAD(P)H oxidases of the cardiovascular system, which were first identified in phagocytes [9], are membrane-associated enzymes that catalyze the one electron reduction of oxygen using NADH or NADPH as the electron donor. The $\mathrm{p} 22^{\text {phox }^{2}}$ subunit (CYBA gene) is essential for the assembly and activation of the $\mathrm{NAD}(\mathrm{P}) \mathrm{H}$ oxidase, and plays a major role in NADPHdependent $\mathrm{O}^{2-}$ production in the vessel wall [22]. In addition to diet, physical activity, hormones, growth factors, and physical forces, the overall ROS production may be influenced by genetic factors. The CYBA gene demonstrates a common functional variant which results in a substitution of Tyr for His at residue 72 (C242T) of the p22 phox , that could disrupt heme binding at the active site [18]. The presence of the $242 \mathrm{~T}$ allele exerts a dominant effect resulting in significantly reduced vascular NADH /NAD $(\mathrm{P}) \mathrm{H}$ oxidase activity in both genotypes, i.e., heterozygous $\mathrm{CT}$ and homozygous TT [13]. Initial evidence links low levels of p $22^{\text {phox }}$ in normal vessels to $\mathrm{p} 22^{\text {phox }}$ up-regulation in subjects with atherosclerosis and hypertension [1]. On the other hand, CT and TT patients exhibited an increased rate of angiographic worsening (coronary vessels) at a mean 2.5 year follow-up after a baseline coronary angiography [6]. However, methodological factors and different definitions of disease end-points may have contributed to these controversial results. Therefore, uncertainty still remains over whether this p22 ${ }^{\text {phox }}$ gene polymorphism actually influences atherogenesis and later steps of progression of coronary atherosclerosis. Thus, in an attempt to determine whether the phenotypic impact of $\mathrm{p} 22^{\text {phox }}$ gene variation is associated with coronary artery disease (CAD) in Italy, we investigated the frequency of CYBA genotypes in a group of Caucasian Italians. The cohort was sub-divided on the basis of their coronary angiograms, and was made up of 276 patients with coronary atherosclerosis, defined as CAD Patients, and 218 healthy adults, defined as Controls. Since the genetic basis of CAD may have a direct effect on setting off the disease process, or a modifying effect on the development of the process once it has started, gene frequencies were also assessed according to single-vessel or multivessel disease as well as on the basis of age at clinical coronary artery disease onset.

\section{Methods}

\subsection{Study population}

We recruited 494 consecutive Caucasian Italians presenting at our University Hospital with typical chest pain (recent onset). They were referred to our Cardiology Unit to undergo coronary angiography. Angiographically documented CAD was found in 276 of them (CAD patients), while normal vessels were found in the remaining 218 subjects (Controls). Informed consent was obtained from all the participants, and the study was approved by the Ethics Board of the Genova University Hospital. Risk factor assessment included a physician-administered, pre-formed questionnaire about health behavior in order to acquire information regarding previous cardiovascular medical history, incidence of cardiovascular risk factors, and medication being taken at admission. Arterial hypertension was defined either by chronic treatment, or, with regards to untreated patients, by the finding of systolic blood pressure $>160 \mathrm{~mm} \mathrm{Hg}$ or of diastolic blood pressure $>90 \mathrm{~mm} \mathrm{Hg}$ on two consecutive measurements. Diabetes Mellitus was defined as fasting blood sugar $>126 \mathrm{mg} / \mathrm{dL}$, glycosylated hemoglobin $>7.5 \%$, or antidiabetic therapy; while hyperlipidemia was defined either by chronic treatment, or by serum total cholesterol $>220 \mathrm{mg} / \mathrm{dL}$. Smoking habit included subjects who were current cigarette smokers $(>2$ pack-years) or who had quit smoking but who had a previous habit $>2$ pack-years. Specially trained nurses measured height, weight, body mass index (BMI) $\left(\mathrm{Kg} / \mathrm{m}^{2}\right)$ and blood pressure using a standardized protocol at our Institute. A history of premature ischemic heart disease was defined as a cardiac event taking place in a first-degree relative and occurring at a (relatively) young age [i.e., $\leqslant 55]$. Subjects were excluded if there was consanguinity within the study population, chronic ( $\geqslant 6$ month period) intake of antioxidants or of dietary supplements, or concomitant diagnosis of chronic co-morbidities (cancer, chronic renal or liver failure), since these conditions are likely to promote a robust alteration in the redox balance. Angiographic documentation of CAD in our study required the presence of at least one major epicardial coronary vessel with $\geqslant 70 \%$ luminal obstruction (CAD patients). Our CAD patients were further sub-grouped to detect whether the $\mathrm{p} 22^{\text {phox }} \mathrm{C} 242 \mathrm{~T}$ polymorphism represented a risk factor for a specific subset of these patients. This was done on the basis of age at clinical onset of ischemic heart disease $(\leqslant 55$ years and $\geqslant 65$ years), extent of coronary atherosclerosis (single vessel vs multivessel disease), and lesion severity (presence of at least 1 coronary vessel with a $\geqslant 98 \%$ lesion). Our choice of the two age-based subgroups ( $\leqslant 55$ years and $\geqslant 65$ years) is arbitrary and only reflects our effort to separate patients with true premature onset of clinically overt coronary atherosclerosis 
from those without it. Controls were defined as healthy adults with normal coronary arteries at angiography, or as having vessels containing irregularities causing $<70 \%$ reduction in lumen diameter.

\subsection{Genotyping}

The CYBA genotypes were analyzed on genomic DNA that was isolated from $10 \mathrm{~mL}$ EDTA anticoagulated peripheral blood. Genotyping was performed by a polymerase chain reaction (PCR)-based method. Briefly, we carried out PCR amplification of a 348 bp fragment from our study subjects using primers, as described elsewhere [14]. Restriction fragment length polymorphism (RFLP) was used to analyze this polymorphic site in the $\mathrm{p} 22^{\text {phox }}$ gene. The $\mathrm{C} \rightarrow \mathrm{T}$ mutation in exon 4 of the CYBA gene produces a RsaI digestion site that makes 188 and $160 \mathrm{bp}$ fragments, whereas RsaI does not cut the PCR product in the wild type. The digestion products were separated on a $2.5 \%$ agarose gel, and bands were measured with an image analyzer system (GeneGenius Syngene Cambridge, UK) and referred to a standard molecular weight $\Phi \mathrm{gX} 174$ Marker 9 (MBI Fermentas, Milano, Italy).

\subsection{Statistical analysis}

Data regarding age, BMI, serum fibrinogen, protein and HDL-cholesterol plasma values are presented as mean \pm SEM. Differences between demographic details and categorical data in Table 1 were assessed by unpaired Student's $t$ test and by Fisher's exact test. Analysis of variance (ANOVA) was used to assess the association between genotypes and baseline characteristics. Chi-square analysis was used to test deviations of genotype distribution from Hardy-Weinberg equilibrium, and to determine whether there were any significant differences in allele or genotype frequencies between CAD patients and Controls. The criteria for statistical significance was set at $p<0.05$.

\section{Results}

\subsection{Baseline genotype in relation to environmental factors}

C242T polymorphism was obtained from $276 \mathrm{CAD}$ patients and 218 Controls. Neither group had a genotype distribution that deviated significantly from what was expected for a population in Hardy-Weinberg equi- librium (Controls: $\chi^{2}=0.092 ; D F=1, p=0.9$; CAD Patients: $\chi^{2}=2.731 ; D F=1, p>0.3$ ). Demographic information for Controls and CAD populations is shown in Table 1. Both the proportion of male subjects and the mean age within the CAD patient group were significantly higher than what was observed in the Control group. The percentage of affected patients who had a personal history of arterial hypertension, of diabetes mellitus, or of hyperlipidemia was statistically higher than in the Control group. Similarly, mean values for serum fibrinogen, for total protein and for HDL-cholesterol differed between CAD patients and Controls.

The presence of the $\mathrm{C} 242 \mathrm{~T}$ allelic variants in the 494 study subjects (either as a whole, or sub-divided into CAD patients and Controls) had no effect on the mean plasma levels of LDL-cholesterol, total cholesterol, triglycerides, or on the incidence of major cardiovascular risk factors (personal history of arterial hypertension, of hyperlipidemia, of diabetes mellitus, smoking status, or family history of ischemic heart disease) (data not reported).

\subsection{Baseline genotype in relation to CAD status}

When genotype results were stratified by CAD status (Table 2), we found an increased prevalence of the $\mathrm{CT} / \mathrm{TT}$ genotype in CAD patients as compared to Controls, with a $\mathrm{T}$ allele frequency respectively of 0.400 and of $0.332(p<0.01)$.

\subsection{Genetic polymorphism related to pattern of $C A D$}

Next, we examined whether the frequency of the C242T mutation among CAD patients differed between those with single vessel $(n=121)$ and those with multivessel (two or three stenosed vessels; $n=155$ ) disease. We found no significant relationship between CT/TT genotype and the extent of CAD $(p=N S)$. With regards to the pre-defined criteria of CAD lesion severity ( lesion $\geqslant 98 \%$ ), we demonstrated that more CAD patients with the CT/TT genotype ( $n=110 / 154)$ had severe stenotic lesions than CAD patients with the CC genotype ( $n=44 / 154)(p<0.05)$, as reported in Table 3. 
Table 1

Baseline characteristics of genotyped CAD patients and controls in our study

\begin{tabular}{lccc}
\hline Variables & $\begin{array}{c}\text { Patients } \\
(n=276)\end{array}$ & $\begin{array}{c}\text { Controls } \\
(n=218)\end{array}$ & P value \\
\hline Age, y & $65.5 \pm 0.6$ & $62.2 \pm 1.0$ & $<0.01$ \\
Male sex, \% & $83.2 \%$ & $67.9 \%$ & $<0.01$ \\
Body Mass Index $\left(\mathrm{Kg} / \mathrm{m}^{2}\right)$ & $26.2 \pm 0.2$ & $26.0 \pm 0.3$ & $\mathrm{NS}$ \\
Smokers, \% & $71.6 \%$ & $77.2 \%$ & $\mathrm{NS}$ \\
Art. Hypertension, \% & $69.1 \%$ & $56.3 \%$ & $<0.05$ \\
Hyperlipidemia, \% & $73.1 \%$ & $52.3 \%$ & $<0.01$ \\
Family History of IHD, \% & $19.8 \%$ & $14.2 \%$ & $\mathrm{NS}$ \\
Systolic BP, mmHg & $133.2 \pm 1.3$ & $134.4 \pm 1.6$ & $\mathrm{NS}$ \\
Diastolic BP, mmHg & $78.2 \pm 0.7$ & $79.2 \pm 0.8$ & $\mathrm{NS}$ \\
Resting HR, beats/min & $68.1 \pm 0.8$ & $73.4 \pm 1.3$ & $<0.01$ \\
Total protein, g/dl & $6.7 \pm 0.07$ & $7.0 \pm 0.6$ & $<0.01$ \\
Serum fibrinogen, mg/dl & $376.1 \pm 9.2$ & $333.2 \pm 9.3$ & $<0.01$ \\
HDL-cholesterol, mg/dl & $44.6 \pm 0.9$ & $51.7 \pm 1.2$ & $<0.01$ \\
Diabetes Mellitus, \% & $26.2 \%$ & $13.5 \%$ & $<0.01$ \\
\hline Values are expressed as: percentage; plus-minus values are mean \pm S.E.; \\
IHD: ischemic heart disease; BP: blood pressure; HR: heart rate; NS: not \\
significant.
\end{tabular}

Table 2

Genotype distribution of the T allele in CAD patients and controls

\begin{tabular}{lllccc}
\hline Genotype $(\%)$ & $\begin{array}{l}\text { CAD Patients } \\
(n=276)\end{array}$ & $\begin{array}{l}\text { Controls } \\
(n=218)\end{array}$ & DF & Chi-Square & P Value \\
\hline CC & $33.3(92 / 276)$ & $45(98 / 218)$ & & & \\
CT/TT & $66.7(184 / 276)$ & $55(120 / 218)$ & & & \\
T allele frequency & 0.400 & 0.332 & 1 & 6.949 & $<0.01$ \\
\hline
\end{tabular}

Table 3

$\mathrm{T}$ allele distribution in CAD patients according to: Presence/Absence of at least one $\geqslant 98 \%$ stenosis in the coronary vessels

\begin{tabular}{llllll}
\hline Genotype $(\%)$ & $\begin{array}{l}\text { Stenosis } \geqslant 98 \% \\
(n=154)\end{array}$ & $\begin{array}{l}\text { No stenosis } \geqslant 98 \% \\
(n=104)\end{array}$ & DF & Chi-Square & P Value \\
\hline CC & $28.5(44 / 154)$ & $40.4(42 / 104)$ & & & \\
CT/TT & $71.5(110 / 154)$ & $59.6(62 / 104)$ & & & \\
T allele frequency & 0.425 & 0.365 & 1 & 3.898 & $<0.05$ \\
\hline
\end{tabular}

\subsection{Genetic polymorphism in CAD patients as related to time of onset of clinical coronary artery disease}

Lastly, we observed that within the subgroup of CAD patients with single vessel disease, those with early clinical onset of ischemic heart disease ( $n=36$ : age $\leqslant 55$ years) had a significantly increased prevalence of $\mathrm{CT} / \mathrm{TT}$ genotypes as compared to patients with late onset of ischemic heart disease $(n=48$ : age $\geqslant 65$ years) $\left(\chi^{2}=5,404 ; D F=1 ; p<0.05\right)$ (Table 4$)$.

\section{Discussion}

Over the last few years, it has been shown that in addition to proteins and lipids, even simple chemi- cal molecules, such as $\mathrm{O}^{2-}$ and other ROS work as molecular switches for physiological and pathological cellular processes such as growth, migration, inflammation and apoptosis. Thus, regulation of vascular $\mathrm{NAD}(\mathrm{P}) \mathrm{H}$ oxidases, which are a source of $\mathrm{O}^{2-}$, is potentially relevant to atherogenesis and to the progression of atherosclerotic lesions. Berry demonstrated that $\mathrm{NAD}(\mathrm{P}) \mathrm{H}$ oxidases and xanthine oxidases were a relevant source of $\mathrm{O}^{2-}$ in arterial vessels [5]. The p22 $2^{\text {phox }}$ protein is essential for the assembly and activation of the $\mathrm{NAD}(\mathrm{P}) \mathrm{H}$ oxidase, and furthermore, it plays a major role in $\mathrm{NAD}(\mathrm{P}) \mathrm{H}$-dependent $\mathrm{O}^{2-}$ production in the vessel wall. We initially concentrated our efforts on characterizing the $\mathrm{C} 242 \mathrm{~T}$ polymorphism because $\mathrm{p} 22^{\text {phox }}$ expression in vascular tissue was found to increase as atherosclerosis progresses. Along the same lines, Schächinger demonstrated that the C242T poly- 
Table 4

T allele distribution in two subgroups of our study population according to age

\begin{tabular}{lllccc}
\hline Subgroups & $\begin{array}{l}\text { Age } \leqslant 55 \text { years } \\
\% \text { CT }+ \text { TT }\end{array}$ & $\begin{array}{l}\text { Age } \geqslant 65 \text { years } \\
\% \text { CT }+ \text { TT }\end{array}$ & DF & Chi-Square & P Value \\
\hline Controls Subjects & $57.6 \%(38 / 66)$ & $50.4 \%(57 / 113)$ & & & NS \\
CAD patients & $73.7 \%(56 / 76)$ & $60.7 \%(68 / 112)$ & & & NS \\
Monovessel CAD & $75 \%(27 / 36)$ & $47.9 \%(23 / 48)$ & 1 & 5.404 & $<0.05$ \\
Multivessels CAD & $72.5 \%(29 / 40)$ & $70.3 \%(45 / 64)$ & & & NS \\
CAD $\geqslant 98 \%$ & $77.1 \%(37 / 48)$ & $63.7 \%(35 / 55)$ & & & NS \\
\hline
\end{tabular}

morphism plays a role in regulating the endotheliumdependent vasodilator function. He suggested that there may be a link between a blunted flow-dependent dilation within normal and diseased vessels and the presence of the allelic CC genotype in 93 patients referred for routine diagnostic catheterization [19]. Accordingly, we decided to test whether the genetic "protective" effect of carrying T alleles was relevant with regards to decreased coronary atherogenesis and progression of atherosclerosis in a group of Caucasian Italians. Family studies are more powerful than transversal observations which include cases (CAD patients) and control subjects (Controls) [20]. We chose a Case-controllike study, even though vulnerable to spurious result, on account of the criteria we used to define the CAD phenotype for our study, i.e., angiographically documented coronary disease. Strikingly, our data suggest that: 1) bearing the CT/TT genotype is significantly associated with the presence of coronary atherosclerosis in our population; and that 2) among CAD patients, the CT/TT genotype is also associated with premature onset of coronary atherosclerosis and with a more frequent finding of at least one $\geqslant 98 \%$ stenosis in a coronary vessel.

\subsection{Genetic polymorphism and angiographic parameters}

The finding that the T allele is related to worse coronary anatomy in our Italian subjects was unexpected. It is tempting to speculate that while enhanced production of ROS in the vascular endothelium is relevant to early atherogenesis, ROS generation may play a different role in later steps of atherosclerosis. Reduced ROS production (associated with carrying $\mathrm{T}$ allele) in the diseased vessels of patients with CAD may be sensed as a signal for reduced vascular SMC survival. In fact, some studies suggest that elevated ROS levels, and specifically $\mathrm{O}^{2-}$, are mitogenic to SMCs and stimulate pro-survival kinase systems, thus acting as both antiapoptotic and intracellular signaling molecules in order to maintain proliferation $[2,11]$. SMC-depleted plaques are more prone to progression through erosion or disruption of their caps [4,21]. If we consider that plaque progression is associated with clinical manifestations of coronary atherosclerosis, and that thicker fibrous caps protect against contact with the blood, then the decreased number of SMCs associated with reduced intracellular generation of ROS in subjects with lower $\mathrm{NAD}(\mathrm{P}) \mathrm{H}$ oxidase activity may be viewed as a potentially dangerous mechanism in a stage of progression towards occlusion in coronary vessels. Recently, the knock-out mice for a subunit of the NAD(P)H oxidase complex ( $\left.\mathrm{p} 47^{\text {phox }}\right)$ exhibited an exacerbated pattern of inflammation as compared to the wild-type mice [23]. Our finding of an increased number of CAD patients with $\geqslant 98 \%$ lesion in carriers of $\mathrm{T}$ allele is in line with this interpretation, and suggests that this polymorphism is associated with a specific pattern of CAD development. This data is consistent with a previous report which demonstrated increased angiographic progression of CAD at 2.5 years, associated with the presence of this mutant allele [6]. In that study, the CAD population consisted of 313 subjects of the LCAS study. Those CAD patients had at least one coronary lesion causing $30 \%$ to $75 \%$ stenosis [6]. Similarly to what was reported by Cai et al. [7] in 689 Australian Caucasians, we were able to demonstrate that our Caucasian Italians with early clinical onset of ischemic heart disease were more frequently carriers of the $\mathrm{T}$ allele than late onset patients. Since the chance of a genetically-related component of CAD risk is more likely to trigger the disease at an early age, our observations imply that the C242T polymorphism is not neutral for the clinical expression of early onset CAD. Our data, together with those reported by Cai et al. [7] and by Cahilly et al. [6], are in contrast with previous investigations which highlighted discrepancies regarding the vascular risk related to carrying $\mathrm{T}$ alleles. In fact, Inoue et al. reported that carrying $\mathrm{T}$ alleles has a protective effect on coronary risk [14], while Gardemann et al. [10] and Li et al. [15] did not confirm this finding. Ethnic variation definitely plays a role in different genotype frequencies among these studies. Further confirmation of our findings is 
needed to understand whether $\mathrm{p} 22^{\text {phox }}$ modulation is an important mechanistic target that needs to be explored in order to develop novel therapeutic options to fight the progression of atherosclerosis.

\subsection{Limits of the study}

Our study includes results that were derived from subgroups with small numbers of subjects, thus lacking power. Larger study groups of CAD patients with premature clinical coronary atherosclerosis are required. There is a lower likelihood among younger patients that certain genotype combinations associated with impaired survival can introduce a bias in the prevalence estimates of genotypes. Complementary strategies that we intend to apply also include performing prospective gene-association studies, in which unrelated healthy Caucasian Italians will be prospectively followed-up over the years to establish whether this $\mathrm{p} 22^{\text {phox }}$ polymorphism is associated with a different incidence of cardiovascular events.

\section{Acknowledgments}

We thank Valerie Frances Perricone for editorial assistance. This study was supported in part by a grant from the Italian Ministry of University and Scientific and Technological Research, Rome, Italy: No. MM06098221 made available through the Department of Internal Medicine, Cardiology, of the Genova University School of Medicine. We are particularly indebted to the nursing staff of the Division of Cardiology for their assistance in collecting samples from the study subjects.

\section{References}

[1] H. Azumi, N. Inoue, S. Takeshita, Y. Rikitake, S. Kawashima, Y. Hayashi et al., Expression of NADH/NADPH oxidase p22phox in human coronary arteries, Circulation 100 (1999), 1494-1498.

[2] A.S. Baas and B.C. Berk, Differential activation of mitogenactivated protein kinases by $\mathrm{H}_{2} \mathrm{O}_{2}$ and $\mathrm{O}^{2-}$ in vascular smooth muscle cells, Circ Res 77 (1995), 29-36.

[3] B.M. Babior, Phagocytes and oxidative stress, Am J Med 109 (2000), 33-44.

[4] M.R. Bennett, G.I. Evan and S.M. Schwartz, Apoptosis of human vascular smooth muscle cells derived from normal vessels and coronary atherosclerotic plaques, J Clin Invest 95 (1995), 2266-2274.
[5] C. Berry, C.A. Hamilton, M.J. Brosnan, F.G. Magill, G.A. Berg, J.J. McMurray et al., Investigation into the sources of superoxide in human blood vessels: angiotensin II increases superoxide production in human internal mammary arteries, Circulation 101 (2000), 2206-2212.

[6] C. Cahilly, C.M. Ballantyne, D.S. Lim, A. Gotto and A.J. Marian, A variant of p22(phox), involved in generation of reactive oxygen species in the vessel wall, is associated with progression of coronary atherosclerosis, Circ Res 86 (2000), 391-395.

[7] H. Cai, N. Duarte, D.E. Wilcken and X.L. Wang, NADH/ NADPH oxidase p22 phox C242T polymorphism and coronary artery disease in the Australian population, Eur J Clin Invest 29 (1999), 744-748.

[8] M.K. Cathcart, Regulation of superoxide anion production by NADPH oxidase in monocytes/macrophages: contributions to atherosclerosis, Arterioscler Thromb Vasc Biol 24 (2004), 23-28.

[9] S.J. Chanock, L.R. Faust, D. Barrett, C. Bizal, F.E. Maly, P.E. Newburger et al., . $\mathrm{O}^{2-}$ production by B lymphocytes lacking the respiratory burst oxidase subunit $\mathrm{p} 47 \mathrm{phox}$ after transfection with an expression vector containing a p47phox cDNA, Proc Natl Acad Sci USA 89 (1992), 10174-10177.

[10] A. Gardemann, P. Mages, N. Katz, H. Tillmanns and W. Haberbosch, The p22 phox A640G gene polymorphism but not the C242T gene variation is associated with coronary heart disease in younger individuals, Atherosclerosis 145 (1999), 315-323.

[11] K.K. Griendling and D.G. Harrison, Dual role of reactive oxygen species in vascular growth, Circ Res 85 (1999), 562-563.

[12] K.K. Griendling and G.A. FitzGerald, Oxidative stress and cardiovascular injury: Part I: Basic Mechanisms and In Vivo Monitoring of ROS, Circulation 108 (2003), 1912-1916.

[13] T.J. Guzik, N.E. West, E. Black, D. McDonald, C. Ratnatunga, R. Pillai et al., Functional effect of the $\mathrm{C} 242 \mathrm{~T}$ polymorphism in the $\mathrm{NAD}(\mathrm{P}) \mathrm{H}$ oxidase $\mathrm{p} 22$ phox gene on vascular superoxide production in atherosclerosis, Circulation 102 (2000), 1744 1747.

[14] N. Inoue, S. Kawashima, K. Kanazawa, S. Yamada, H. Akita and M. Yokoyama, Polymorphism of the NADH/NADPH oxidase $\mathrm{p} 22$ phox gene in patients with coronary artery disease, Circulation 97 (1998), 135-137.

[15] A. Li, A. Prasad, R. Incemoyer, C. Satorius, N. Epstein, T. Finkel et al., Relationship of the C242T p22phox gene polymorphism to angiographic coronary artery disease and endothelial function, Am J Med Genet 86 (1999), 57-61.

[16] M. Maytin, J. Leopold and J. Loscalzo, Oxidant stress in the vasculature, Curr Atheroscler Rep 1 (1999), 156-164.

[17] Z.S. Nedeljkovic, N. Gokce and J. Loscalzo, Mechanisms of oxidative stress and vascular dysfunction, Postgrad Med J 79 (2003), 195-200.

[18] C.A. Parkos, M.C. Dinauer, L.E. Walker, R.A. Allen, A.J. Jesaitis and S.H. Orkin, Primary structure and unique expression of the 22-kilodalton light chain of human neutrophil cytochrome b, Proc Natl Acad Sci USA 85 (1988), 3319-3323.

[19] V. Schächinger, M.B. Britten, S. Dimmeler and A.M. Zeiher, $\mathrm{NADH} / \mathrm{NADPH}$ oxidase $\mathrm{p} 22^{\text {phox }}$ gene polymorphism is associated with improved coronary endothelial vasodilator function, Eur Heart J 22 (2001), 96-101.

[20] M.S. Spence, P.G. McGlinchey, C.C. Patterson, A.R. Allen, G. Murphy, U. Bayraktutan et al., Investigation of the C242T polymorphism of $\mathrm{NAD}(\mathrm{P}) \mathrm{H}$ oxidase $\mathrm{p} 22$ phox gene and ischaemic heart disease using family-based association methods, Clin Sci 105 (2003), 677-682. 
[21] J.C. Tsai, M. Jain, C.M. Hsieh, W.S. Lee, M. Yoshizumi, C. Patterson et al., Induction of apoptosis by pyrrolidinedithiocarbamate and $N$-acetylcysteine in vascular smooth muscle cells, J Biol Chem 271 (1996), 3667-3670.

[22] M. Ushio-Fukai, A.M. Zafari, T. Fukui, N. Ishizaka, K.K. Griendling, .p22phox is a critical component of the superoxide-generating NADH/NADPH oxidase system and regulates angiotensin II-induced hypertrophy in vascular smooth muscle cells, J Biol Chem 271 (1996), 23317-23321.

[23] F.A. van de Loo, M.B. Bennink, O.J. Arntz, R.L. Smeets, E. Lubberts, L.A. Joosten et al., Deficiency of NADPH oxidase components p47phox and gp91phox caused granulomatous synovitis and increased connective tissue destruction in experimental arthritis models, Am J Pathol 163 (2003), 1525-1537. 


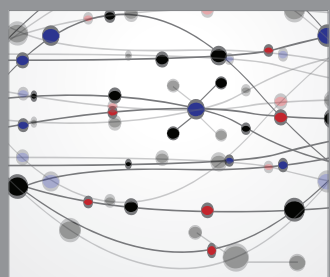

The Scientific World Journal
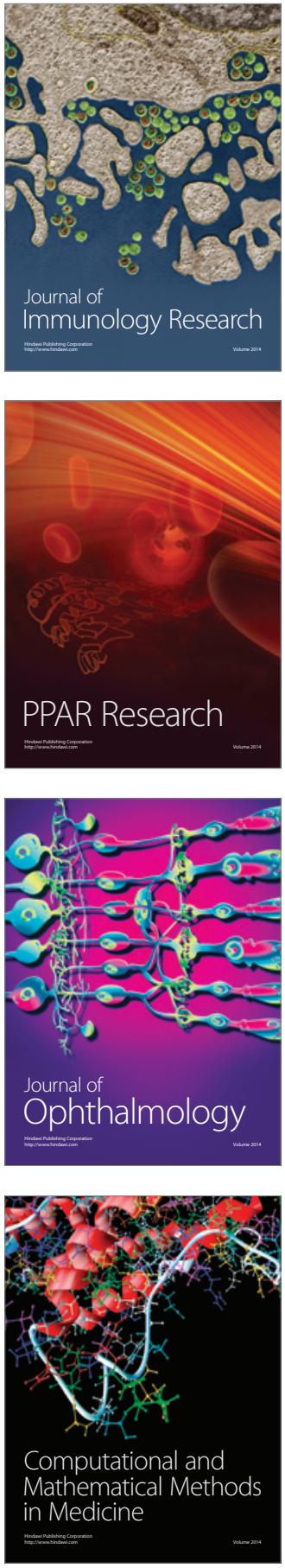

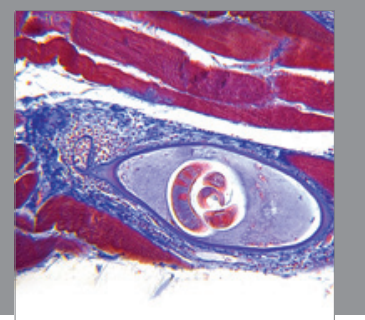

Gastroenterology

Research and Practice
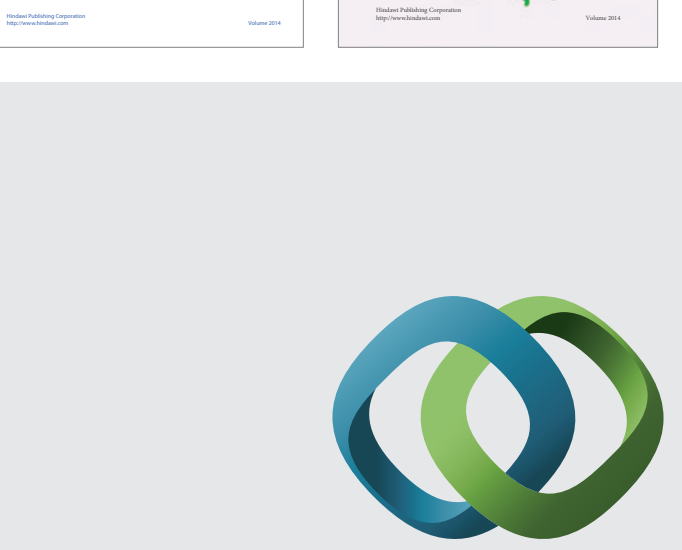

\section{Hindawi}

Submit your manuscripts at

http://www.hindawi.com
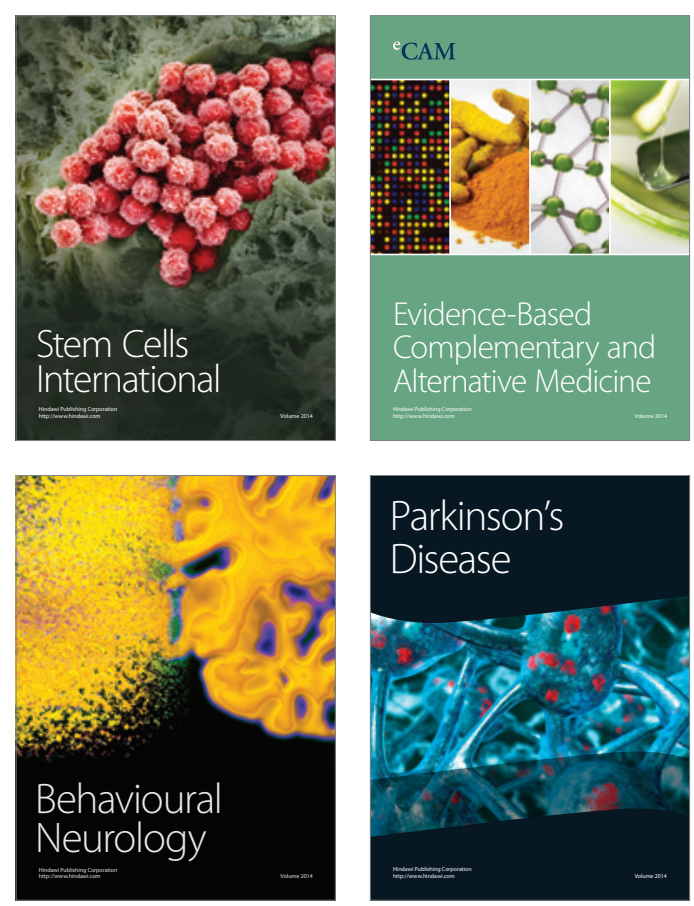

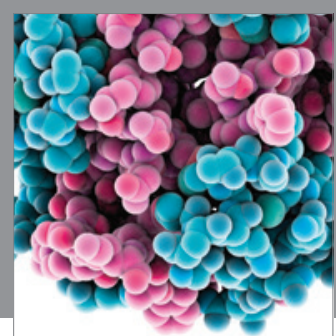

Journal of
Diabetes Research

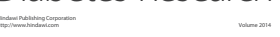

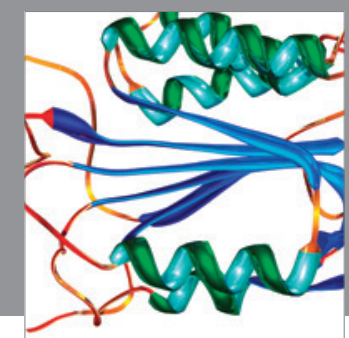

Disease Markers
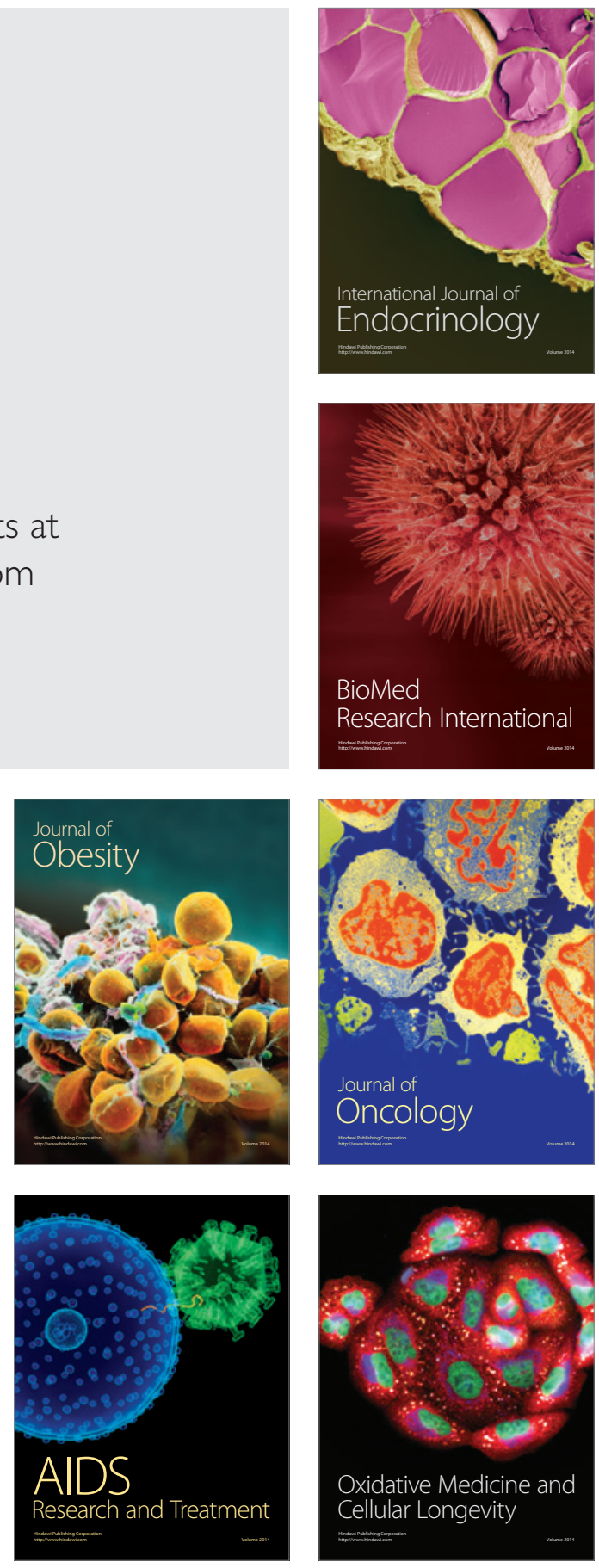